\title{
Single tooth replacement using a ceramic resin bonded fixed partial denture: A case report
}

Haluk Baris Kara'

Filiz Aykent ${ }^{1}$

\begin{abstract}
This article describes the use of an all ceramic resin-bonded fixed partial denture as a conservative solution for the replacement of an incisor. It is a minimally invasive technique that does not discolor the abutment teeth. (Eur J Dent 2012;6:101-104)
\end{abstract}

Key Words: Minimally invasive technique, IPS Empress 2, replacement of mandibular lateral incisor, resin bonded fixed partial denture.

\section{INTRODUCTION}

Patients with congenitally missing teeth present a therapeutic challenge. ${ }^{1}$ When replacing an incisor, the dentist has the following options: (1) an implant-supported single crown, (2) a conventional fixed partial denture (FPD), or (3) a resin-bonded fixed partial denture (RBFPD). ${ }^{2}$ The implant-supported crown may not be advisable when available bone volume is minimal, or when the adjacent root is in close proximity. ${ }^{3}$ RBFPDs can be used successfully to replace missing teeth. ${ }^{4,5}$ Clinical guidelines and indications for modified ceramic resin-bonded fixed partial dentures include (1) vi-

- 1 Department of Prosthodontics, Faculty of Dentistry, Selcuk University, Konya, TURKIYE.

- Corresponding author: Dr. Haluk Barıș Kara, Selcuk University, Faculty of Dentistry, Department of Prosthodontics, Campus / KONYA, TURKIYE Phone: +90-332-2410041/1186

Fax: +90-332-2410062

e-mail: halukbarislahotmail.com tal and noncarious abutment teeth, (2) a missing maxillary lateral incisor or mandibular central or lateral incisor, (3) minimal or no occlusal contacts on the abutment framework and pontic, and (4) shallow incisal guidance to avoid a steep vertical overlap. ${ }^{6}$ Mandibular incisors are involved primarily in protrusive movement, with more than $40 \%$ not involved in occlusion. ${ }^{7,8}$ Both glass-ceramic and high-strength oxide ceramic can be used to produce optical properties similar to those observed in natural teeth. ${ }^{9}$ It has been shown that the highest failure load, exceeding $2000 \mathrm{~N}$, was found for FPDs veneered with DC-Zirkon ceramic. FPDs of IPS Empress and In-Ceram Alumina showed the lowest failure loads, below $1000 \mathrm{~N}$, whereas intermediate values were observed for FPDs of IPS Empress 2 and In-Ceram Zirconia. ${ }^{10}$ The primary disadvantage of a zirconium framework is its opaque appearance. ${ }^{11}$ Metal-ceramic RBFPDs have shown successful outcomes after a 10-year follow-up period. ${ }^{12} \mathrm{~A}$ noted common problem with 
metal-ceramic RBFPDs has been the gray color of the incisal third of the abutment teeth caused by cast metal lingual retainers. ${ }^{13,14,15}$

This clinical report describes an alternative treatment for replacement of mandibular lateral incisor with an IPS Empress 2 resin-bonded fixed partial denture.

\section{CASE REPORT}

A 42-year-old man presented with a missing mandibular right lateral incisor and right canine due to partial anodontia (Figure 1). The following prosthetic treatment options were considered: (1) an implant-supported single crown, (2) a conventional FPD, and (3) an RBFPD. Implant replacement was excluded as an option because the patient declined the several surgical procedures required. The conventional FPD was also excluded because the abutment teeth were vital and intact. Thus, to minimize unnecessary tooth preparation, the use of the RBFPD was suggested and accepted by the patient. Before preparation, radiographic evaluations were conducted to ensure that the designated abutments had adequate periodontal health and root support. The tooth reduction was made by using flame-shaped chamfer and shoulder diamond rotary cutting instruments

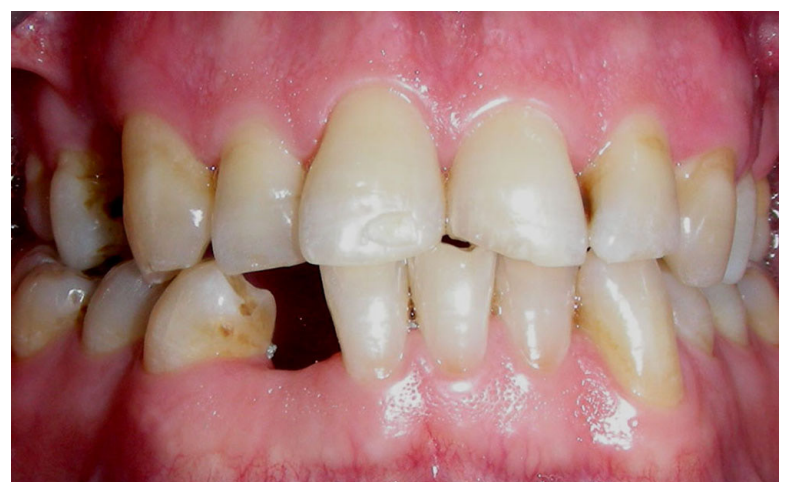

Figure 1. Preoperative frontal view.

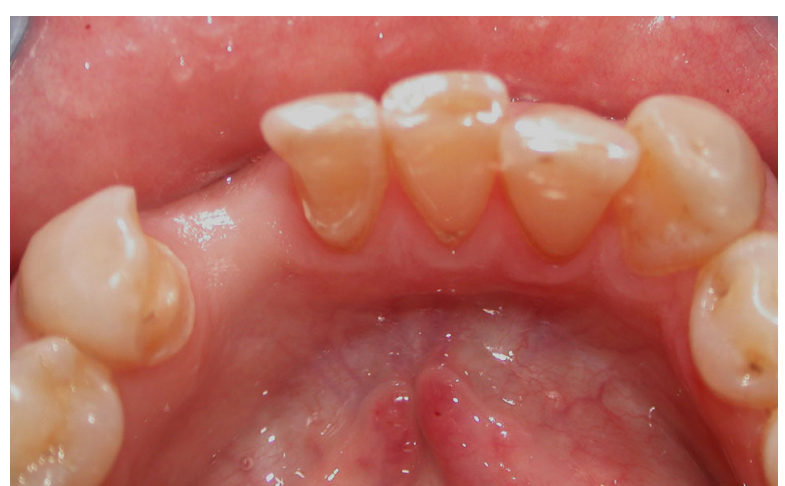

Figure 2. Lingual view of abutment tooth preparation.
(TPS 2 preparation kit, Komet, Gebr. Brasseler Gmbh \& Co. KG, Lemgo, Germany). The lingual surfaces of the abutment teeth were reduced approximately $0.5 \mathrm{~mm}$, with a supragingival shoulder finish line approximately $1 \mathrm{~mm}$ from the crest of tissue and $1 \mathrm{~mm}$ from occlusal reduction (Figure 2). During preparation of the lingual surface, the labiolingual thicknesses of the incisal edges of abutment teeth were carefully evaluated.This factor provided equal thickness to prevent fracture. ${ }^{13}$ The heights of proximal contours were reduced to allow the insertion of the restoration and provide increased tooth surface available for bonding. A proximal chamfer finish line ending approximately $1 \mathrm{~mm}$ above the cemento-enamel junction and 1 $\mathrm{mm}$ in depth was established (Figure 3). The proximal extension of preparation toward the labial surface was prepared just lingual to the contact areas. ${ }^{16}$ Vinyl polysiloxane impression (Virtual Refill Fast Set, Ivoclar Vivadent AG, FL- 9494 Schaan, Liechtenstein) of the mandibular arch was made. Impressions were made of the maxillar arch with irreversible hydrocolloid (Kromopan; LASCOD SpA, Firenze, Italy]. A maxillo mandibular occlusal registration (Regisil Rigid; Dentsply Intl, York, PA) was made. The definitive casts were mounted on an articulator. Provisional restorations were made by placing microfilled composite resin directly on prepared unetched tooth surfaces, finished, and polished. At the second visit, the provisional restorations were easily removed with a scaler.

All-ceramic RBFPD was fabricated with IPS Empress 2 (Ivoclar Vivadent, Schaan, Liechtenstein) (Figure 4). At the initial trial insertion, complete seating of the prosthesis, marginal adaptation of each retainer, tissue contact, form of the substructure for the pontic, and occlusion were assessed. Subsequently, the premature contacts

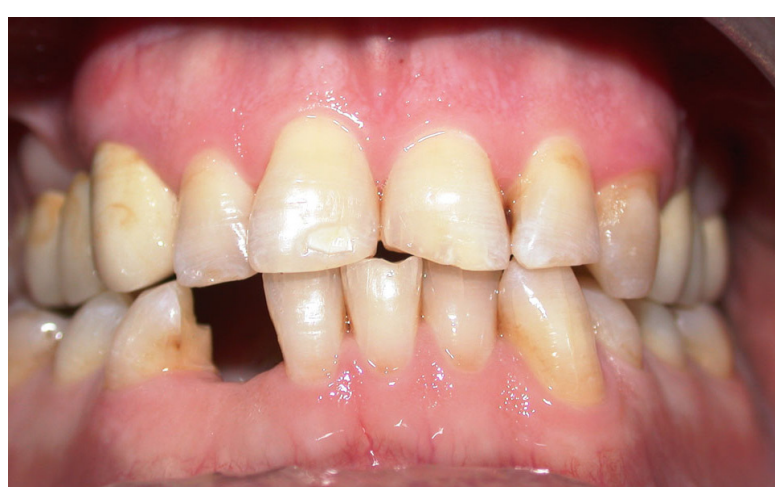

Figure 3. Frontal view of preparation on premolar 
were eliminated, and the shade of the pontic was determined and recorded. During the veneer porcelain application, only glaze (Ivoclar Vivadent) was applied to lingual aspect of the prosthesis to prevent over contouring of lingual wings. After veneer porcelain was added to the pontic, a second trial evaluation session was conducted. All characteristics described previously were reviewed, and final approval from the patient was obtained. ${ }^{17}$

The dentin and enamel were completely etched with 37\% phosphoric acid (Email Preparator; Ivoclar Vivadent) for 20 seconds. The dentin was conditioned (Syntac Adhesive and Primer and Heliobond; Ivoclar Vivadent) and the IPS Empress 2 all-ceramic RBFPD was luted with a dual polymerizing composite (Variolink II; Ivoclar Vivadent, Schaan, Liechtenstein) in accordance with manufacturer's instructions. The luting agent was applied to the preparation and internal surface of the restoration with a disposable brush. The restoration was inserted with moderate pressure, and excess luting agent was carefully removed with an explorer. Under slight pressure, the restoration was light-polymerized from 3 different direc-

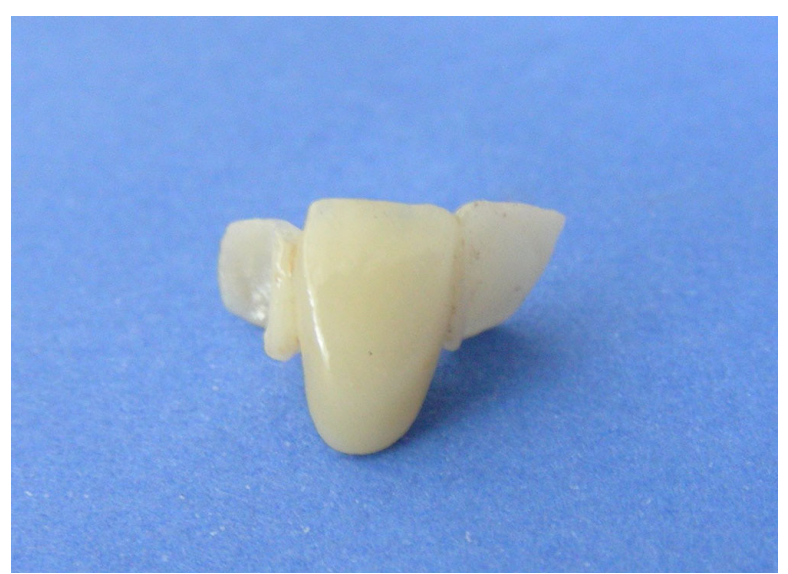

Figure 4. IPS Empress 2 RBFPD on definitive cast.

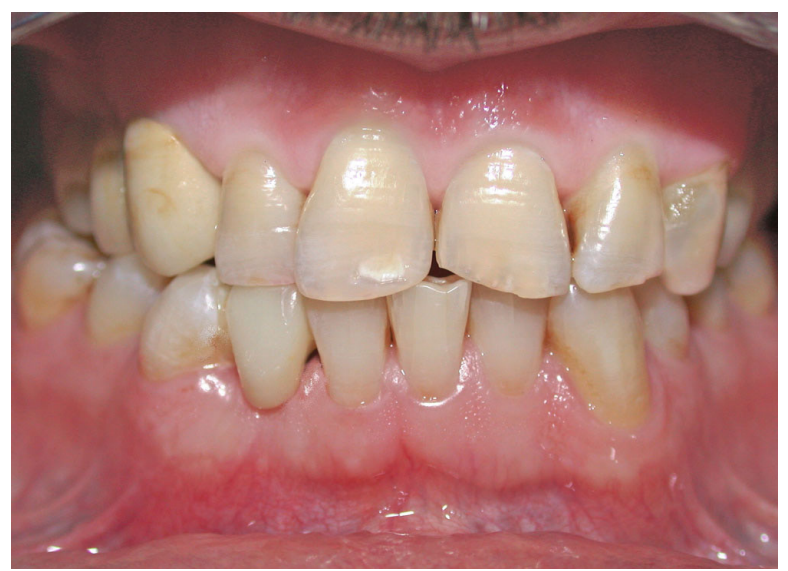

Figure 5. Frontal view of definitive restoration. tions (buccal, lingual, and occlusal) for 40 seconds (Bluephase; Ivoclar Vivadent, Schaan, Liechtenstein). After polymerization was complete, excess cement was removed from the margins with a periodontal scaler (HyLite, Hamburg, NY). After cementation, the occlusion was carefully evaluated, and adjustments were made on the restoration with an intra-oral porcelain finishing set (Edenta Porcelain Veneer Kit; Edenta AG Dental Produkte, Lugano, Switzerland) (Figure. 5). After cementation of the IPS Empress 2 RBFPD, routine recall visits were performed 4 times over a 2-year period. In evaluations of the IPS Empress 2 RBFPd at these visits, no functional or aesthetic problems were reported by patients.

\section{SUMMARY}

This clinical report describes indications, abutment tooth preparation, and clinical procedures involved in the fabrication of an IPS Empress 2 RBFPD, which provides a conservative solution for the replacement of mandibular lateral incisors.

\section{REFERENCES}

1. Ben-Bassat Y, Brin I. Skeletal and dental patterns in patients with severe congenital absence of teeth. Am J Orthod Dentofacial Orthop 2009;135:349-356.

2. Hagiwara $Y$, Matsumura H, Tanaka S, Woelfel J. Single tooth replacement using a modified metal-ceramic resinbonded fixed Partial denture: A clinical report. J Prosthet Dent 2004;91:414-417.

3. Chiche GJ, Pinault A. Esthetics of anterior fixed prosthodontics Chicago: Quintessence; 1994.p.48-50.

4. Kern M. Clinical long-term survival of two-retainer and single-retainer all-ceramic resin-bonded fixed partial dentures. Quintessence Int 2005;36:141-147.

5. Ries S, Wolz J, Richter EJ. Effect of design of all-ceramic resin-bonded fixed partial dentures on clinical survival rate. Int J Periodontics Restorative Dent 2006;26:143-149.

6. Barrack G. Recent advances in etched cast restorations. $J$ Prosthet Dent 2005;93:1-7.

7. Donegan SJ, Kna pFJ. A study of anterior guidance. J Prosthodont $1995 ;$ 4:226-232.

8. Ferrario V F, Sforza C, Miani A, Serrao G. Kinesiographic three - Dimensional evaluation of mandibular border movements: a statistical studyin a normal young non patient group. J Prosthet Dent 1992; 68:672-676. 
9. Rosentritt M, Ries S, Kolbeck C, West- phal M, Richter EJ, Handel G. Fracture characteristics of anterior resinbonded zirconia-fixed partial dentures. Clin Oral Investig 2009;13:453-457.

10. Tinschert J, Natt G, Mautsch W, Augthun M, Spiekermann $\mathrm{H}$. Fracture resistance of lithium disilicate,alumina, and zirconia based three unit fixed partial dentures: a laboratory study. Int J Prosthodont 2001;14:231-238.

11. Derand P, Derand T. Bond strength of luting cements to zirconium oxide ceramics. Int J Prosthodont 2000;13:131-135.

12. Ries S, Wolz J, Richter EJ. Effect of design of all-ceramic resin-bonded fixed partial dentures on clinical survival rate. Int J Periodontics Restorative Dent 2006;26:143-149.

13. Goodacre C J, Bernal G, Rungcharassaeng K, Kan J Y. Clinical complications in fixed prosthodontics. J Prosthet Dent 2003;90:31-41.

14. Besimo C. Resin-bonded fixed partial denture technique: results of a medium-term clinical follow-up investigation. J Prosthet Dent 1993;69:144-148.

15. Barrack G, Bretz W A. A long-term prospective study of the etched-cast restoration. Int J Prosthodont 1993;6:428-434.

16. Chow T W, Chung R W, Chu F C, Newsome P R. Tooth preparations designed for posterior resin-bonded fixed partial dentures: a clinical report. J Prosthet Dent 2002;88:561-564.

17. Turker S B, Guvenli S Y, Arikan A, Replacement of two mandibular central incisors using a zirconium resin-bonded fixed partial denture: A clinical report. J Prosthet Dent 2005;94:499-503. 